\title{
The Issue that Feminism is Stigmatized on the Internet in China and Some Possible Solutions
}

\author{
Chengxiaoyan Hong ${ }^{1, \dagger}$, Yang Hong ${ }^{2, \dagger}$, Jiawen $\mathrm{Li}^{3, *}{ }^{*}$, Qingyan Zhang ${ }^{4, \dagger}$ \\ ${ }^{1}$ Shanghai United International School Jiaoke Campus \\ ${ }^{2}$ Nanjing Foreign Language School \\ ${ }^{3}$ Beijing Foreign Studies University \\ ${ }^{4}$ United World College Changshu China. \\ Corresponding Authors. Email: 20900020@bfsu.edu.cn \\ Those authors contributed equally.
}

\begin{abstract}
Recent years have witnessed an increasing number of people who have been raising the awareness of gender equality. At the same time, however, misinterpretations and misunderstandings arise and soon become rampant in online discussions. Aggressive advocates for feminism somewhat conspire to the stigmatization of feminism, a process that insults a group of people by stereotypes and remains the procedure. It leads to a result that makes it even harder for women to protect their rights since outsiders do not realize the issues and joke at them. This review focuses on the form of stigmatization of feminism and rationale against a Chinese backdrop of feminism, and it is expected to offer insights into feminism in China with an all-around picture in a long run. Additionally, the comparison between western countries and China is illustrated to showcase that the unique domestic situation underlies the stigmatization of feminism, and distinguishes the differences between different cultures. For further research, solutions to the issue are expected to be raised based on this literature review.
\end{abstract}

\section{Keywords: Feminism, Stigmatization of feminism, Chinese feminism, Internet}

\section{INTRODUCTION}

As Wang pointed out, that the true meaning of feminism is that they hope to achieve equality and freedom with male rights through the law [1]. Feminism is a group of people who appeal to equality compared with males and call for fewer restrictions about the stereotype of women. Feminism focuses on eliminating the differences that are generated by society, instead of biological and objective distinction. To be specific, in China, many companies consider that female workers may be pregnant in the future, which means they will rest for months with payment. Companies are lucrative, concerned with their benefit so they are prone to hire more male employers for saving, which conspires to severe issues of inequality and discrimination in job interviews. In the light of the domestic situation, Wang stated that both males and females are all the same in mankind, and females ought to be able to seek their freedom and rights. Thus, feminism, as a matter of fact, is a social revolution driven by the public. From another perspective, it is a success to see people start to be aware of the inequality issues and speak out with courage, support, and understanding in China. It is related to present education, sci-technology so that people can introspect what is under the social issues.

With the development of the Internet, feminism has become a popular social topic in China. According to Liu, it was alleged that owing to the theoretical selfweakness of feminism in China, the misleading of media, and the increase of equality consciousness, the stigmatization shows frequently on the Internet [2]. Stigmatization represents insulting a specific group of people and retaining the process of insulting. Although technology helps females protect their rights and appeal to more people, it also amplifies the weakness of feminism and misinterprets the perspectives in an event on the Internet, resulting in more misunderstanding and miscommunication in feminism. In some cases, feminism is deemed to be aggressive and perilous. Since few people really have a comprehensive understanding of feminism, such kind of misunderstanding and misrecognition renders feminists increasingly difficult to speak for and clarify themselves. 
Specifically, ordinary people may form a negative impression even when women are safeguarding rights in reasonable manners, and consider them as aggressive women who are insane and sensitive. On account of superficial recognition and sarcastically amusing public communication, feminism is scarce to be taken in serious context on the internet.

Take one specific case based on the Chinese culture: “女权”(nv quan) and “打拳”(da quan). The two phrases share similar pronunciation and become a pun. The first one, "nv quan" stands for feminism. Nevertheless, the other represents the behavior that a few women behave aggressively and verbally attack others with extreme opinions. In the English context, "da quan" means "boxing". Against this backdrop, protection of rights and the pursuit of equality are inclined to be exaggerated as violent actions, when most netizens are brought up in a typically patriarchal society. This sarcastic pun implies that the majority of the netizens, including a mass of un-awakened women, do not consider feminism to be an impetus for equality and social justice. As hundreds of millions of netizens play language games and use the pun, the brink of equality is blurred and there is an incessant intangible intrusion into the domain of female rights. Therefore, feminism is gradually losing its utterances. A common phenomenon could be, that when women try to deal with some issues or argue about equality, some other people may joke at them: Are you going to box? It is obvious that people try to use "boxing" to insult women when they are protecting their rights by comparing them to an irrational action, implying the stigmatized characteristics of feminism.

The value of this literature review lies in that it combines the history and national condition in China to analyze the stigmatization phenomenon on the Internet. It includes present cases and news to explain further and support the ideas, showing its timeliness. Additionally, it provides a detailed and clear background such that readers without any related knowledge can understand from the definition of feminism to the stigmatization phenomenon on the Internet. Specifically, beginning from the current situation of feminism in China which contains the development of Chinese feminism, neutral aesthetics of contemporary Chinese Women, and the system and practice of protection, and then introduces the stigmatization, which includes forms, possible reasons, and impact. Last but not least, possible solutions are raised to give basic references for further research, analyzing from the education perspective and new media perspective.

\section{LITERATURE REVIEW}

\subsection{Introduction to Chinese Feminism}

\subsubsection{The development of Western and Chinese feminism}

In order to provide in-depth analysis as well as a reasonable solution for the issue, the authors consider it compulsory to exploit the root of feminism and then shed light on its contemporary vitality.

The Subjection of Women is John Stuart Mill's fabulous work, considered as "a Bible of Feminist Movement before WWI". [3] Mill pointed out that the whole process of human society from primitive ignorance to civilization and progress is discriminating against women. In primal society, the male was physically stronger and defeated nature, while the female was weaker and inclined to be dependent on the male. However, when the chariot of social development advanced to the advent of a legal and civilized mechanism, it was indeed a matter of course that physical edges were exaggerated to a form of intentional maintenance of the status of men, endowing men with unique political and social rights. Mill believes that women's submission from physical weakness to the legal establishment is a convention driven by ideas and prejudices. It not only lacks rational argument and historical basis but has gradually become customary beliefs and universal feelings, which is an alternative manifestation of slavery [4]. Despite the continuous progress of human society and the everincreasing renewal of the social system, women's subservient status has not changed, instead, they have become "legal family slaves." While Mill contributed to the foundation of feminism in some other respects, the authors choose to remain focused on the critical issue in China, only to cite pertinent perspectives.

The development of Chinese feminism cannot be discussed without a person, Mao Zedong. Wang Xiaorong pointed out that Mao Zedong's thoughts on women's liberation provide vital ideological resources for the analysis and solution of contemporary Chinese feminism. Mao put women's liberation in the first place in the early stage, expressing concerns about the oppression of marriage and family and the traditional social system. Later, Mao Zedong turned his way of thinking about women's liberation to materialism. Mao discovered that private ownership was the root cause of the oppression of women, holding the idea of abolishing this policy. Besides, after Mao chose Marxism as his political guide, the gender issue gradually became subsidiary. According to Mao, women's liberation was attributed to class liberation, so only when the class was liberated could women be liberated. He also started to think about the reality and developed a Marxist outlook on women in accordance with China's conditions. Marx 
believes that the issues of women cannot be discussed separately from the history of human society. Mao Zedong's views on women inherited part of the Marxist theory of women liberation, with Chinese characteristics. He considers that the root cause of women's oppression is the intricate result of the interaction between class discrimination and gender discrimination.

\subsubsection{Contemporary Chinese Women in Social Context}

Neutral standard of beauty of contemporary Chinese women is an example of the development of contemporary feminism in China. In The Thinking of Chinese Modern Women from Neutral Aesthetic from the Perspective of Feminism, Ma Jiao points out that neutral aesthetics, which combines the characteristics of women and men does not mean that women have lost their independent aesthetic value, but they have shifted their focus from the aesthetic standards given by men to their own needs. For example, Li Yuchun's victory in the TV show "Super Girl" is an expression of women's own desires. With short hair, single eyelids, Li always appears on stage with shirts and flat shoes, instead of graceful soft long hair [5].

Additionally, the trend of clothing design embodies feminist ideas. According to Ma Jiao, in the "neutralization" phenomenon of women's clothing, people have added many elements that reflect the equality of men and women in the design of women's clothing, hoping to eliminate the difference between the sexes through external clothing forms. Neutral clothing design, such as punk style, lady suits, is an external expression of independence and confidence of contemporary women.

The System and Practice of the Protection of Women's Rights and Interests in China is another example. In the Symposium Summary of System and Practice of the Protection of Women's Rights and Interests with Chinese Characteristics in the New Era, Zhen Xiling points out that in November 2019, China Women's Federation announced some Amendments to the Law on the Protection of Women's Rights and Interests. The amendments include the system and practice of guaranteeing women's employment rights, political rights, women's rights in marriage and family, women's land rights protection, and women's personal rights [6].

\subsection{The stigmatization of Feminism}

\subsubsection{The forms of stigmatization of feminism}

Though mainly focusing on the analysis of pastoral feminism, unique digital feminism that was raised on the Chinese Internet in recent years, the section will also be comparing pastoral feminism and the concept of feminazi to further improve the understanding of the issue.

Pastoral feminism, a form of toxic digital feminism that is typically seen on Chinese social media platforms such as Zhihu (similar to quora) and Weibo (similar to Twitter), is the main representation of stigmatization of feminism on the Internet in China [7]. According to Li Jinke, Pastoral feminists are defined as those who do not understand "real" feminism, but arm themselves with the flag of so-called Western feminism to attack people online [8]. A typical example of pastoral feminism would be the case of Papi Jiang. As a Chinese comedian, Papi Jiang is known for making videos on the Internet to reflect on social issues and family relationships and has established her image as a strong and independent woman. However, after her child followed her husband's family name, Papi received wide criticism from pastoral feminists, blaming her for being submissive to patriarchy [9]. This example is a miniature of how pastoral feminism works - finding a target and then attacking it under the name of feminism. Eventually, the widespread of pastoral feminism on the Internet has caused the space for the discourse of real feminism squeezed and led to public suspicion of feminism.

A possible comparable to pastoral feminism is the concept of "feminazi" in western society. The term was first popularized by Rush Limbaugh and was defined as any female who is intolerant of any point of view that challenges militant feminism. He also specifically targeted feminism's advocacy on abortion rights, stating that "abortion is the single greatest avenue for militant women to exercise their quest for power" [10]. It is not hard to see the similarity between pastoral feminism and feminazi - both are radical forms of feminism that focus on issues typical to each country: the targeting of abortion in the United States, and the focuses of unique feminism issues such as the naming rights for children and bride-price issues in China.

\subsubsection{Possible reasons behind the stigmatization of feminism}

Several reasons will be identified in this section to explain why feminism is stigmatized. Respectively, they represent the reason on the individual level, from the social level, and from feminism itself.

Fearing feminism is the first reason that feminism is often stigmatized on the Internet. Being a feminist is not as easy as simply declaring an identity, but also involves addressing uncomfortable topics and facing injustice and oppression. Among many controversies, there outstand Baumgardner and Richards who alleged that even at the beginning of the Second Wave, women were resistant to acknowledge discrimination. The 
resistance of discrimination leads to the lack of awareness, and the lack of awareness leads to the fearing of feminism, and the fearing of feminism leads to the ignorance of feminism, which makes women vulnerable and gullible to the mainstream's shape of feminism [11].

Continuing with the last paragraph, fearing feminism leads to the ignorance of feminism, and the misleading portrayal of feminism in the mainstream culture eventually causes the ignorance into stigmatization. According to Baumgardner and Richards, feminism is more often described by what it isn't than by what it is. In "I Am Not a Feminist, but...": How Feminism Became the F-Word, Moi demonstrated this view through his teaching experience in Duke University, where students refused to identify themselves as feminist because they believe other people would then regard them as strident, domineering, aggressive, and intolerant and -worst of all - that they must hate men. [11]. It can be seen from this example that with mainstream's false portrayal, feminism has somehow become a synonym of misandry, and a disconnect between the original idea of feminism - the fight for freedom, power, and equality of women - and the prevailing view of feminism has been created. Because of this disconnection, people who have the potential to become feminists are deviated from the idea of feminism, as they do not want to be regarded as misandrists even though they stand with the belief that women and men are equal. The deeper reason behind this disconnection can be traced down to the fact that demagoguery has become part of the mainstream American culture and the way media presents information to people nowadays. Consequently, the notion of feminism is often distorted from its real purpose with conservatives' comment on feminism using a hyperbolic manner - a typical example would be Robertson's statement that Feminists encourage women to leave their husbands, kill their children, practice witchcraft, become lesbians, and destroy capitalism [11].

In addition to the fact that feminism is always falsely presented in the mainstream culture, the division inside feminists themselves is another reason that causes the stigmatization. In the 1990s during the period of first-wave feminism, a whole range of "new" feminism theories emerged - from "equity feminism" to "power feminism" to "tough cookie feminism" - which, in general, all start by attacking feminism [10]. With the massive variety of different types of feminism, the advocates for each feminism felt the need to distinguish themselves from other feminisms to demonstrate its superiority so much that eventually, they became more and more extreme-Christina Hoff Sommers, a leading feminist basher, once proclaimed that gender feminists condescend to, patronize, and pity the benighted females who, because they have been socialized in the sex/gender system, cannot help wanting the wrong things in life, indicating that with the divisions inside feminism, the ideology of some feminists has become problematic.

\section{CONCLUSION}

It's conspicuous that feminism is severely stigmatized on the internet in China. The development of feminism in China was originally promoted by Mao Zedong, and contemporary Chinese feminism has been constantly improved in terms of beauty standards and laws [12]. The pastoral feminism presented on the Internet in China is armed with the banner of so-called Western feminism, which can be compared with the feminazi in the West. To put it in a nutshell, the fear of feminism, the misleading portrayal of feminism in the mainstream culture, and the divisions inside feminists themselves are three possible reasons leading to the current stigmatization of feminism. The research purpose of this literature review is mainly to analyze the essence of the stigmatization of women's rights on the Internet in China, think about some possible solutions, so as to better promote women's rights positively. The authors' future research direction will turn to the stigmatization of feminism in daily life offline in China, analyzing and thinking about feasible solutions from the perspectives of society, culture, language habits, and history.

\section{REFERENCES}

[1] Wang, Xilong. (2018). On the Definition Analysis and Philosophical Interpretation of Feminism". Journal of Writers and Artists of China. January,2018.

[2] Liu, Han-jing, PAN Li. (2020). An Analysis of the Stigmatization of Feminism in China' $\mathrm{s}$ Virtual Society and the Solutions. JOURNAL OF HARBIN UNIVERSITY Feb. 2020 Vol.41 No.2.

[3] John Stuart Mill. (1994). The Subjection of Women. Dover Publications.

[4] Huang Lijuan. (2019). "Father of Feminism" John Stuart Mill's Discourse on Women. National Social Sciences Database, 1674-5450 (2019) 060121-07.

[5] Ma, Jiao. (2019). "The Thinking of Chinese Modern Women from Neutral Aesthetic from the Perspective of Feminism". Drama House, 1007 0125(2019)29-0195-04.

[6] Zhen, Xiling. (2020). "Symposium Summary of System and Practice of the Protection of Women's Rights and Interests with Chinese Characteristics in the New Era". Journal of Chinese Women's Studies, 1004-2563 (2020)01-0 125-04. 
[7] Wan, Jun. (2019). "Feminism stigmatization analysis in Weibo content". Journal of HaiNan Normal university (Social Science) May.2019.

[8] Li, Jinke. (2018). "A Controversial Existence: Chinese Pastoral Feminism". Advances in Social Science, Education and Humanities Research, volume 236. Retrieved September 11, 2021.

[9]. Di, Xuanya. (2020). "Papi irritated feminists by giving her child her husband's family name" The Beijing News. Retrieved September 11, 2021, from https://m.bjnews.com.cn/detail/158918773315432. html.

[10] Moi, T. (2006). "I Am Not a Feminist, but...": How Feminism Became the F-Word. PMLA, 121(5), 1735-1741. Retrieved September 11, 2021, from http://www.jstor.org/stable/25501655.

[11] Baumgardner, J. \& Richards, A. (2000). Manifesta: Young women, feminism, and the future. New York: Farrar, Straus and Giroux.

[12] Wang, Xiaorong. (2020). "The historical interpretation and contemporary value of Mao Zedong's views on women: from the interpretation of $\mathrm{Pu}$ Lean, a Western scholar". Journal of the Party School of the Nanjing Municipal Committee of the Communist Party of China, 1672 1071(2020)01-0018-06. 